\title{
TEORIA DA ATIVIDADE E MEDIAÇÃO TECNOLÓGICA: EXEMPLAR DE UMA PRÁTICA DESENVOLVIDA NO AMEM
}

\author{
Taís Fim Alberti (UFSM/RS) \\ Fábio da Purificação de Bastos (UFSM/RS)
}

\begin{abstract}
RESUMO
Com o surgimento da Internet, os Ambientes Virtuais de Ensino-Aprendizagem (AVEA) representam um recurso didático que pode viabilizar os processos de formação, oportunizando acesso a escolarização. Esses AVEA permitem um trabalho didático-metodológico integrando diversas ferramentas que contribuem na realização de uma prática dialógica e problematizadora. Etnografamos a construção da prática docente mediada por um AVEA (AMEM) em um curso de formação continuada, onde observamos que as atividades de estudo e a educação dialógico-problematizadora integradas ao planejamento dos conceitos a serem aprendidos potencializam o processo de aquisição dos conhecimentos teóricos, promovendo desenvolvimento psicointelectual. Destacamos que a diretividade dos professores foi fundamental nessa experiência mediada por tecnologias.
\end{abstract}

\section{AVEA: em busca de novos percursos para a educação}

A educação a distância está tomando forma e inserindo-se no campo educacional como uma nova modalidade escolar, possibilitando que mais pessoas venham buscar formação e qualificação. Ela apresenta-se como uma inovação que pode suprir algumas carências na educação relacionadas ao acesso à escolaridade, tornando-a mais abrangente. Além disso, pode ser mais um meio de potencializar formação para os professores.

Com o surgimento da Internet, a EaD tomou um novo impulso. O que antes era feito por correspondência, rádio ou TV passa ser mediado também pelo computador pessoal conectado, possibilitando comunicação síncrona e assíncrona através dos AVEA. Com sua implementação, muitas questões estão sendo retomadas. Como exemplo podemos citar: a formação continuada, o planejamento, a organização e produção de material didático, as formas de redimensionar o trabalho docente e como conduzir o processo de ensino-aprendizagem mediado por AVEA. Essas são questões importantes, que precisam ser trabalhadas para garantir um ensino diretivo e de qualidade. Nesse novo âmbito, mudam os espaços e tempos de ensinar e aprender. Transforma-se a forma de organizarmos o trabalho escolar. O espaço é outro, e os AVEA surgem como possibilidade para que esse processo se articule.

Conforme Almeida, esses AVEA nos permitem integrar múltiplas mídias e recursos, apresentar informações de maneira organizada, desenvolver interações entre pessoas e objetos de conhecimento, elaborar e socializar produções tendo em vista atingir determinados objetivos (2003, p.05). Denominamos por AVEA um ambiente que possui uma interface para navegação hipertextual que agrega múltiplas mídias, ferramentas de comunicação síncrona e assíncrona com uma proposta pedagógica e estrutura didático-metodológica, localizado em um único sítio (DE BASTOS, MAZZARDO E ALBERTI, 2005).

Na concepção de Silva (2003, p. 56), nesses ambientes, o professor pode, "tornar-se um 
provocador do conhecimento". No AVEA, o professor modifica sua ação modificando seu modo de comunicar em sala de aula. De mero transmissor de saber, parceiro ou conselheiro, ele se torna um formulador de problemas, proponente de situações, arquiteto de percursos, mobilizador de saberes, de inteligências múltiplas e coletivas na construção colaborativa do conhecimento.

De acordo com Valentini e Soares (2005, p.19) o conjunto de atividades, estratégias e intervenções que levam os interagentes a construir e a se transformar juntos é o que há de mais específico nos AVEA. Isso significa que não se trata apenas da mera transposição dos ambientes, recursos e metodologias educacionais trabalhados no modelo presencial, para garantir a eficácia do processo de ensino-aprendizagem mediado pelas tecnologias. Mas sim, é fundamental contemplar, no planejamento institucional e no design do projeto de cada curso ou programa, aspectos específicos da modalidade a distância, para que as mudanças se consolidem e sejam efetivas, assim como uma estrutura didática-metodológica que promova o desenvolvimento cognitivo dos alunos.

Assim, conforme consta no Relatório de Assessoria para a Educação Superior a Distância, é preciso considerar os pressupostos filosóficos e pedagógicos que orientam a estrutura do curso e os objetivos, competências e valores que se pretendem alcançar, aspectos culturais e sócio-econômicos tanto no desenho pedagógico do curso, quanto na definição dos meios de acesso dos alunos; uma dinâmica de evolução do processo de ensino-aprendizagem que incorpore a interação entre alunos e professores e dos pares entre si, bem como o desenvolvimento adequado da avaliação de ensino e aprendizagem e do material didático que deverá subsidiar as aulas. (Brasil/MEC/SEED, 2002).

\section{Sobre a mediação tecnológica: AMEM}

O AMEM foi desenvolvido por uma equipe multidisciplinar (Ensino de Ciências Naturais, Matemática e suas Tecnologias, Pedagogia, Psicologia Informática, Engenharia de Produção e Design) na UFSM, situado na Web, e focado, em princípio, na possibilidade dos professores de Ensino Superior e Pós-Graduação atuarem na perspectiva da Investigação Ação Escolar e da Educação Dialógica-Problematizadora. Destina-se à educação presencial, semipresencial e a distância (MÜLLER e DE BASTOS, 2004). Atualmente está em fase de testes a versão 2.0 do AMEM, podendo ser acessada no endereço <http://amem-ead.ce.ufsm.br/>.

A opção pela utilização de tecnologias pertencentes ao movimento de software livre está baseada na convicção de que a exclusão digital só será verdadeiramente combatida se todos os aspectos da mesma forem confrontados. Desta forma, a utilização de software livre multiplataforma é crucial, pois permite que qualquer tipo de instituição, com qualquer base tecnológica instalada, possa usufruir o ambiente desenvolvido, ou até mesmo melhorá-lho ou adaptá-lo conforme necessidades de cada curso (DE BASTOS, MÜLLER e CORDENONSI, 2005).

O AMEM pode ser acessado de qualquer navegador da Internet, no endereço $<$ http://amem.ce.ufsm.br. > sendo que, para navegar no ambiente e acessar suas ferramentas, é necessário efetuar um cadastro, presente na página inicial. Não exige de quem for trabalhar com o ambiente um amplo conhecimento das tecnologias envolvidas. Além disso, apresenta um tutorial, caso os navegadores sintam-se obstaculizados para manusear determinadas ferramentas, otimizando o seu trabalho no ambiente. 
Na versão atual do AMEM, os usuários podem assumir quatro perfis diferentes: o de professor e o de aluno, centros do processo de ensino-aprendizagem, e o de administrador, encarregado da manutenção do ambiente e o de visitantes (FERNANDEZ, 2003). Existem seis módulos principais: pessoal (manutenção do cadastro dos participantes), comunicação (ferramentas síncronas e assíncronas), disciplinas (acesso às atividades de estudo), biblioteca (ficam disponíveis os materiais escolares para acesso e leitura), e ajuda (manual de ajuda para entendimento das funcionalidades). Essas ferramentas estão disponíveis ao trabalho do professor e do aluno, na busca de uma educação que atenda aspectos dialógicosproblematizadores, visando uma prática para a liberdade. Essas funcionalidades são apresentadas da seguinte forma:

a) Pessoal - É uma área destinada ao usuário, onde ele pode preencher um cadastro com seus dados pessoais, mudar senha quando necessário, enviar mensagens e agendar algum compromisso, prova, trabalho.

b)Comunicação - Oportuniza a comunicação entre educador/educando e educando/educando no ambiente, através das ferramentas "Fórum", "Salas de discussão" e "Mensagens", além da possibilidade de "Editar notícia" e "Mural".

c) Disciplinas - Com perfil diferenciado para professor e aluno, o professor programa a implementação da aula, o aluno tem acesso à "Programação", ao referencial bibliográfico e às "Atividades de Colaboração" e "Extraclasse". Neste módulo, apresentam-se: "Disciplinas oferecidas", "Turmas em que estou matriculado", "Disciplinas que ministro" (professor). Em relação à programação, atividade de colaboração, atividade extraclasse e agendamento de atividade, descrevemos abaixo suas funções:

Programação: horário e programação da aula com especificação dos Momentos

Pedagógicos no tempo didático, editada pelo professor.

Atividade de Colaboração: introdução ao conteúdo que será desenvolvido em aula. Seguindo as referências bibliográficas, o aluno responde (no campo específico) uma questão orientadora, antes da implementação da aula. Assim, a Atividade de Colaboração possibilita ao aluno participação ativa do processo de organização do próximo encontro dialógico através de sugestões, compartilhando bibliografias, entre outros.

Atividade Extraclasse: tarefa escolar, de entendimento retrospectivo, centrada no conceito central da aula, a qual deverá ser enviada para o ambiente na data e horário previsto. Pode ser colocada na forma de uma problematização a ser resolvida pelo aluno.

Agendamento de Atividade: é a organização, pelo professor, nos tempos didáticos, dos componentes presenciais e a distância e seus acoplamentos. Permite "controle" do início e fim, tanto para datas, quanto para horários das tarefas; enfim, existem prazos a serem cumpridos pelos alunos.

d) Biblioteca - Disponibilização de material e/ou indicações bibliográficas. Ao ser selecionada a opção "Biblioteca", é exibida uma área destinada à busca de uma determinada bibliografia, juntamente com uma lista de assuntos. Cada assunto agrupa suas respectivas bibliografias. Pode-se também aqui obter maiores informações sobre as bibliografias disponibilizadas no ambiente AMEM, ler as bibliografias disponibilizadas eletronicamente e até mesmo fazer uma busca por uma referência específica. O recurso Biblioteca é mais um diferencial do AMEM, pois não é encontrado em todos os AVEA (MAZZARDO, 2005).

e) Ajuda - Orienta na navegação pelo AMEM. É composto pelos botões: "Ajuda", "Sugestões, críticas e solicitações", "Tutorial".

f) Sair - Possibilita sair do AMEM, da turma ou da disciplina conforme o dispositivo em que o participante se encontra.

É importante destacar as áreas que cabem ao trabalho escolar do professor e do aluno no 
AMEM. A partir de "Identificação", classifica-se os participantes em professor e aluno e direciona-os para seus devidos módulos. O professor é responsável pela coordenação das atividades propostas aos alunos. Por esse motivo, é levado ao módulo de coordenação, onde lhe é dado acesso aos módulos de planejamento, implementação, registro e programação. O aluno é direcionado para o módulo de implementação, resultante do planejamento proposto pelo professor, ao qual ele teve oportunidade de contribuir por meio dos módulos de comunicação e cooperação, coordenados sempre pelo professor, na fase de planejamento (MÜLLER e DE BASTOS, 2004).

Como nossas práticas didáticas nesses ambientes têm sido pautada também pela preocupação com os procedimenos didático-metodológicos, destacaremos neste trabalho a Educação Dialógico-Problematizadora e a Teoria da Atividade.

\section{Escolarização a Distância Dialógica e Problematizadora}

Trabalhar de forma dialógica e problematizadora com os meios tecnológicos comunicacionais é um desafio. Eles disponibilizam uma gama de informações e novas possibilidades que exigem um comprometimento da educação, inclusive porque possibilitam a oportunidade de mais pessoas terem acesso a escolarização.

Assim, a educação no escopo da ciência e da tecnologia tem um lugar de destaque nas transformações da sociedade e na formação dos sujeitos que atuam nela. A adesão a essas tecnologias não deve acontecer de forma incondicional como se fossem solucionar todos os problemas educacionais. Precisamos explorar as potencialidades dos recursos computacionais nas situações de ensino-aprendizagem e evitar o deslumbramento que tende a levar ao uso mais ou menos indiscriminado da tecnologia por si e em si, ou seja, mais por suas virtualidades técnicas do que por suas virtudes pedagógicas. (BELLONI, p. 73, 2003).

Torna-se necessário entender que existem diferenças de uso da tecnologia, conforme aponta Dowbor, pois senão vamos continuar repetindo o que era feito antes: as tecnologias sem a educação, conhecimentos e sabedoria que permitem organizar o seu real aproveitamento, apenas levam-nos a fazer as mesmas coisas. (2001, p. 9). Portanto, não é apenas a tecnologia educacional que precisa mudar, é a própria concepção de ensino que precisa repensar os seus caminhos.

Conseqüentemente, a escola pode, através da rede, assumir novas tarefas. Os professores precisam perceber que para isso as formas de trabalhar também mudam. É no aprender com o digital que eles potencializam mudanças. Assim, o professor terá que saber que, em lugar de substituir, os AVEA podem potencializar sua atuação e seu ofício. Para isso, se faz necessário deixar as práticas transmissivas e disponibilizar-se para o diálogo:

Deixa de ser um mero transmissor de saberes. Deverá converter-se em formulador de problemas, provocador de interrogações, coordenador de equipes de trabalho, sistematizador de experiências e memória viva de uma educação que, em lugar de aferrar-se ao passado (transmissão), valoriza e possibilita o diálogo entre culturas e gerações (MARTíN-BARBERO, 1998, p.23 apud SILVA, 2002, p. 70)

Temos em Freire (1987) que o diálogo é o encontro dos sujeitos que, mediatizados pelo mundo, buscam pronunciá-lo, ou seja, o encontro dos sujeitos para cumprir a tarefa co- 
mum de saber agir. É no diálogo que os sujeitos se encontram para ser mais. Na prática, o diálogo caracteriza a educação problematizadora como aquela realizada com os alunos, uma vez que é inerente à dialogicidade o agir com alguém sobre alguma coisa; portanto, faz-se necessário partir daquilo que é familiar ao aluno, pois dessa forma ele poderá participar efetivamente do processo (ABEGG, 2005).

Por isso, o ato de educar começa quando o professor se pergunta em torno do que vai dialogar com os alunos. O que ele precisa fazer é propor aos alunos, como problemas, situações concretas que por sua vez, o desafiem, exigindo assim respostas, não só no âmbito intelectual, mas também no âmbito da ação (FREIRE, 1987). Estabelece-se assim uma prática educativa dialógica-problematizadora. Para isso, o professor necessita aprender a distinguir quais questões são problemas para si próprio, quais têm sentido em seu processo de aprendizagem dos conteúdos a serem ensinados, e quais terão sentido para os alunos (ABEGG, 2005).

Assim, através da abordagem dialógico-problematizadora não apenas são colocados problemas para serem resolvidos, como também são problematizadas situações que envolvam os conteúdos a serem ensinados e que muitas vezes são dados como prontos e acabados. A partir do entendimento de que problemas são situações que apresentam dificuldades e para as quais não temos respostas prontas e precisamos investigar uma maneira de resolvê-las (GIL PERÉZ \& VADÉS CASTRO, 1997), torna-se necessário assumir uma conduta de investigação, inclusive no escopo da escolarização a distância.

Para desenvolvermos a escolarização a distância dialógica e problematizadora, precisamos superar a visão que temos sobre a aula como um simples repasse ou transmissão de conhecimentos por pessoas mais instruídas. Salientamos que a aula a ser desenvolvida através de um AVEA deve ser trabalhada na perspectiva de um encontro dialógico de ensinoaprendizagem, e não deve ser entendida no seu sentido etimológico de: "aula ser igual a lição". Isso tem levado professores e alunos a entenderem que aprender em situações escolarizadas significa apenas reproduzir os conteúdos programáticos das matérias escolares, tal como lhes foi transmitido durante as aulas. Porém, esse significado de aula está sendo questionado, e mudanças na prática docente podem tornar o processo de ensino-aprendizagem mais qualitativo e com um propósito que ultrapasse a simples transmissão do saber acumulado pela humanidade (RAYS, 2002).

Entendemos então, que a aula nos AVEA deve ser planejada com base em um encontro dialógico-problematizador para que juntos educando e educador exercitem na prática o diálogo de uma forma crítica, onde alunos tenham conhecimento do que acontece ao seu redor e contextualizem o conhecimento científico e tecnológico com suas vivências tornando-os mais comprometidos com sua escolarização e mais participativos nas transformações de nossa sociedade. Poderemos, assim, superar as formas de educação bancária nas aulas e passaremos aos encontros de escolarização dialógica e problematizadora, integrando a organização de atividades de estudo com os demais setores da atividade humana que também constituem espaços produtores de conhecimento e de onde advém a cultura do aluno, o seu conhecimento de mundo.

\section{Sobre a Teoria da Atividade}

A Teoria da Atividade tem seus pressupostos teóricos advindos do enfoque histórico-cultural 
da escola de Vygotsky, sendo difundida por Leontiev, Davidov e outros. Para Davidov (1988) a aprendizagem e o ensino são formas universais de desenvolvimento mental, sendo que 0 ensino propicia a apropriação da cultura e o desenvolvimento do pensamento. Todavia, essa aquisição não se faz de outra forma se não na aprendizagem dos conceitos das diversas áreas do conhecimento. Precisamos nos preocupar com o processo de ensino-aprendizagem dos alunos, seja ele presencial ou a distância, pois a escolarização é a atividade na qual se adquire o domínio de símbolos e instrumentos culturais disponíveis nas sociedades letradas que possibilitam a mediação do aluno com os outros e com o meio ambiente, ampliando a sua ação como ser social.

O termo "atividade de estudo" indica um dos tipos de atividade reprodutiva dos alunos e não quer dizer que seja a única maneira de aprender, pois se aprende nas formas mais diversas de atividades. No entanto, o que diferencia uma atividade de estudo de outras atividades é que a mesma tem um conteúdo e uma estrutura especial, ou seja, ela necessariamente exige um planejamento definido com finalidades a serem alcançadas. Isso designa que a atividade de estudo deve ser diretiva e a principal nas atividades dos alunos, pois a partir da realização das atividades escolares, os alunos desenvolvem a capacidade de organização para outras atividades a serem realizadas por eles. Devido a isso, não podemos dizer que um aluno "pesquisando informações" na Internet, ou fazendo qualquer outra atividade sem orientações obterá aprendizagens, pois não sabemos se aquilo que ele está buscando realmente é necessário para a sua formação. Portanto, o processo de ensino-aprendizagem na modalidade a distância precisa de um acompanhamento rigoroso.

A atividade de estudo é um conjunto de ações e operações mentais ou práticas a serem realizadas pelo aluno. O desenvolvimento de uma atividade de estudo segue uma estrutura para a realização das tarefas de aprendizagem, que devemos considerar na sua realização: a tarefa em si, ações condutoras de aprendizagem e ações como avaliação e controle. Devemos compreender por controle uma forma de acompanhamento sobre o cumprimento das ações. Nessa etapa o professor pode monitorar a realização das tarefas e acompanhar o desenvolvimento dos alunos. Através da avaliação, o professor tem condições de saber se os resultados das ações de estudo correspondem (ou não) e em que medida aos objetivos finais. É a avaliação que informa aos alunos se eles conseguiram solucionar ou não a tarefa de estudo proposta pelo professor (DAVIDOV, 1988).

Essas ações servem para ensinar os conceitos que os alunos precisam aprender durante a escolarização. Se eles aprenderem a realizar as atividades propostas pelo professor, conseqüentemente isso também influirá no seu desenvolvimento psíquico geral e na formação de sua personalidade, bem como na realização de novas tarefas, em que provavelmente terão condições de contextualizar o que aprenderam anteriormente. Assim, a aprendizagem escolar além de promover a aquisição dos conteúdos ou habilidades específicas, consiste também numa via de desenvolvimento psíquico. A atividade de estudo é, portanto, o movimento de formação do pensamento teórico, assentado na reflexão, análise e planejamento, que conduz ao desenvolvimento psíquico (DAVIDOV, 1988).

\section{Curso de Formação Continuada desenvolvido no AMEM}

Durante o desenvolvimento do curso de Formação Continuada pela mestranda Mara Denize Mazzardo e pelo Prof. Dr. Fábio da Purificação de Bastos, etnografamos as atividades esco- 
lares mediadas pelo AMEM, realizadas pelas professoras-alunas. A partir dessas, destacamos alguns apontamentos referentes a essa experiência, estabelecendo relações com a Teoria da Atividade como uma forma possível de orientação psicológica para trabalhos que sejam mediados tecnologicamente. $O$ curso de Formação Continuada foi realizado com professores da Educação Básica da Rede Pública - Região Educacional de Santa Maria - RS, atuantes na Educação Básica, em unidades escolares que têm Laboratório de Informática conectados à Internet.

No âmbito teórico, foi realizada uma modelização didático-metodológica para as habilidades no manejo dos recursos informáticos, a participação, o questionamento, o diálogo, a ação e as reflexões decorrentes das situações de formação. O curso "Produção de Material Didático através da Internet: o saber e o saber ensinável" foi desenvolvido nas modalidades Presencial (14h) e a Distância (26h). As aulas aconteceram nos meses de agosto a outubro de 2004, sendo que a parte presencial foi ministrada na UFSM (MAZZARDO, 2005).

O conteúdo trabalhado foi: a busca de saberes na rede sobre a disciplina de atuação do professor e em consonância com os Parâmetros Curriculares Nacionais (PCN) e a transposição didática; estudo e discussão sobre os PCN e orientações educacionais complementares aos PCN (PCN+); educação mediada pelas tecnologias informáticas livres; a Internet como fonte de informação e saber; onde encontrar os saberes na rede; produção de material didático (MAZZARDO, 2005).

Durante a etnografia desse curso, destacamos as potencialidades da Teoria da Atividade e a EDP no planejamento e implementação de um curso mediado por tecnologias de informação e comunicação, em que os professores-formadores procuraram integrar os conceitos científicos e tecnológicos através de atividades de estudo diretivas, dialógica e problematizadoras, tudo mediado por um AVEA.

\section{Teoria da atividade e EDP: contribuições para práticas mediadas por tecnologias na escolarização a distância}

Com relação ao desenvolvimento da prática docente mediada por tecnologias, encontramos na Teoria da Atividade uma concepção de atividade escolar que se aproxima do que estamos organizando para atividades mediadas tecnologicamente. Acreditamos ser fundamental a orientação do professor durante o processo de ensino-aprendizagem, assim como a necessidade de ensinar a organização conceitual do que precisa ser aprendido pelos alunos a fim de desenvolver com eles o pensamento teórico: um ensino que tenha como objetivo o desenvolvimento cognitivo dos alunos através da formação do pensamento teórico - e que o mesmo saiba contextualizar o que aprendeu durante a resolução de novas atividades. Propomos que isso seja organizado em um encontro dialógico-problematizador, acoplando os recursos tecnológicos de comunicação e informação envolvendo alunos em ações e operações com atividades diretivas. Para isso, se faz necessário que o professor planeje tarefas de aprendizagem e conduza o seu desenvolvimento a fim de organizar o processo de ensinoaprendizagem através de "atividades de estudo" (DAVIDOV, 1988).

Conforme o autor, no processo de estudo com atividades rectoras ${ }^{i}$, os alunos aprendem os conhecimentos e habilidades correspondentes aos fundamentos das formas de consciência social, como também desenvolvem as capacidades surgidas historicamente que estão na base da consciência e do pensamento teórico. Ou seja, a reflexão, a análise e o experimento mental. Isso significa dizer que os conteúdos da atividade de estudo são os conhecimentos 
teóricos.

Assim como foi mencionado anteriormente, as atividades de estudo compreendem um dos tipos de atividade reprodutiva dos alunos e não quer dizer que seja apenas a única maneira de aprender, pois se aprende nas formas mais diversas de atividades. No entanto, o que diferencia uma atividade de estudo de outras atividades é que a mesma tem um conteúdo e uma estrutura especial, ou seja, ela necessariamente exige um planejamento definido com suas finalidades a serem alcançadas.

Isso implica que a atividade de estudo precisa ser diretiva e a principal nas atividades dos alunos. Por esse motivo, acreditamos que as atividades de estudo precisam fazer parte de um trabalho mediado tecnologicamente, pois dessa forma os alunos orientam-se no processo de aquisição do conhecimento sem deixar a aprendizagem por conta apenas destes, sem direcionamento.

Segundo Leontiev (1983), a mente e a consciência são mediadas por ferramentas e objetos, sendo que a atividade humana não pode existir de outra maneira senão em forma de ações ou grupo de ações. Logo, é preciso realizar atividades práticas para que os alunos aprendam e entendam os conteúdos. Portanto, estar vivenciando este momento de formação em situações práticas foi de grande valor formativo para as professoras-alunas, pois ao invés de apenas ouvir sobre tecnologias informáticas, também estavam manuseando e dialogando sobre elas no contexto educacional. Elas não estavam participando de um "cursinho de informática”, e sim estavam trabalhando mediadas por tecnologias informáticas, problematizando conceitos importantes para a sua área de atuação, no âmbito de uma organização didáticometodológica que lhes oportunizou dialogar sobre os conteúdos abordados, tendo o AMEM como mediador desse processo escolar.

Seguindo o mesmo autor, temos que, a atividade surge de necessidades que impulsionam motivos orientados para um objeto. Para que os objetivos sejam alcançados, são necessárias ações e operações. Os motivos para a realização dessas ações precisam ser bem definidos, ou melhor, bem orientados, para que não se realize apenas uma ação mecânica. Para não se tornar uma ação mecânica, a estrutura da organização concreta da atividade humana é determinada pelas necessidades e por motivos relacionados com condições e aos meios para alcançá-los. Para isso, criamos ações e operações. A linha principal da atividade é estar sempre com um caráter dirigido ao objeto: todos seus componentes apresentam um outro conteúdo em forma de objeto e ela mesma, necessariamente, está dirigida para a criação de um certo produto.

Durante o curso de formação continuada, as professoras-alunas sujeitas de uma investigação-ação onde atuamos etnograficamente passaram pela realização de atividades, desenvolvendo tarefas orientadas pelos professores-formadores. As ações deram-se em torno de uma prática mediada através do AMEM, planejada rigorosamente e disponibilizada na Internet.

Portanto, podemos dizer que a necessidade de vir em busca dessa formação foi um fator potencializador para o desenvolvimento cognitivo das professoras-alunas. Pois foi a necessidade de aprenderem a trabalhar mediadas tecnologicamente que as motivou vir em busca dessa formação e enfrentar esse desafio formativo. Isso fez com que o motivo delas estarem participando não fosse em forma de ação mecânica, surgindo de uma necessidade para a 
sua prática docente. Nessa perspectiva, há pessoas que, além de estarem aprendendo, participam e tornam-se agentes críticos do processo de mudança. Para isso, familiarizar-se com essas mediações tecnológicas, seus objetos e fenômenos é necessário, como também é, conhecê-los, para posicionar-se de maneira crítica, com argumentos que garantem sua posição.

Assim, as tecnologias de informação e comunicação a distância (telemática), têm mediado o processo de ensino-aprendizagem. Tais recursos precisam fazer parte do contexto de trabaIho das professoras-alunas e é para aprender a trabalhar com eles que estão em busca de formação. Demonstraram preocupações em relação ao processo de ensino-aprendizagem mediados por um ambiente virtual, pois perceberam que não é tarefa fácil preparar atividades de estudos a distância para os alunos e trabalhar com mediação tecnológica.

As professoras-alunas em formação perceberam não se tratar apenas de "usar" um computador pessoal com seus alunos. Estão aprendendo e conhecendo na prática a trabalharem mediadas tecnologicamente, compreendendo uma organização didático-metodológica organizada em três momentos dialógicos-problematizadores (ABEGG, DE BASTOS, MALLMANN, 2001), assim estruturados: Desafio Inicial (DI), que é a problematização do tema; MeIhor Solução Escolar no Momento (MSEM), onde são trabalhadas os conceitos principais do conteúdo que está sendo desenvolvido; e Desafio mais Amplo (DA), operacionalização dos conhecimentos.

Isso proporcionou a percepção de que os professores precisam orientar seus alunos durante esse processo de ensino-aprendizagem mediado. Para tal, reconhecem que precisam passar por essa formação para estarem aptas a desenvolver com os seus alunos a capacidade de imaginação, observação e raciocínio lógico, agora mediado por um ambiente virtual na Internet.

O aluno precisa do professor para ser conduzido em suas tarefas de estudo. A diretividade por parte do professor, nesse processo também é fundamental. Dessa forma, ao propor as atividades de estudo, ele acompanha a realização, dando suporte aos alunos nos momentos de dificuldade, observando e até mesmo registrando os momentos em que avançaram nas tarefas propostas, percebendo quais atividades precisam ser retomadas nos próximos planejamentos e onde pode avançar nas mesmas. Os registros escritos também precisam fazer parte desse processo. Eles são uma forma de resgate do que foi feito e isso possibilita ao professor investigar a prática escolar reorientando o planejamento das aulas e a preparação de material didático. No AMEM temos essa possibilidade de registro a cada aula na ferramenta: "Registro: Análise da Implementação" que possibilita ao professor fazer os registros após desenvolver as aulas, respondendo questões de pesquisa que considere relevantes investigar ativamente. Processo esse realizado pelos professores-formadores, que, além de desenvolverem atividades diretivas para trabalharem com as professoras-alunas, registravam a cada aula o transcorrer das atividades.

Portanto, são por esses motivos que as tarefas de estudo se diferenciam de outras atividades que os alunos fazem. Por que elas são planejadas com seus conteúdos e finalidades a serem trabalhadas. Devido a isso, não podemos dizer que um aluno "pesquisando" "informações" na Internet, ou fazendo qualquer outra atividade sem orientações, se efetivará em aprendizagens. Pois não sabemos se aquilo que ele está buscando, realmente é necessário para a sua formação. Não temos como "garantir" a aprendizagem sem um acompanhamento 
e uma comprovação de que ele realmente aprendeu.

Podemos dizer também, que a Teoria da Atividade tem caráter problematizador. $\mathrm{E}$ as tarefas a serem propostas podem ser organizadas em forma de problemas. Porém escolher as situações-problemas é fundamental. É preciso saber formulá-las, pois não se formula de forma espontânea. Sendo assim, acreditamos que é possível sair de um modelo de repasse de conhecimentos e chegar a situações de aprendizagem tendo como procedimento didáticometodológico a problematização. Davidov afirma que, no ensino de caráter problemático os conhecimentos não são transmitidos aos alunos, sendo que os conhecimentos são adquiridos por eles em processo de atividade cognoscitiva autônoma em presença de uma situação problemática. Acrescentaríamos ainda: situação-problemática orientada pelo professor (1988, p.181).

O ensino de caráter problematizador pode potencializar maior reflexão e compreensão da situação-problema, promovendo um plano para a ação e uma análise sobre o feito. Essa atividade dialogica-problematizadora era proposta para as professoras-alunas no DI de cada aula, na forma de desafio concreto ou problema a resolver, problematizando os entornos da situação desafiadora, com o intuito de envolvê-las na busca da solução para o desafio colocado. Assim, o AVEA poderá potencializar o desenvolvimento intelectual no momento em que o professor coloca uma situação-problema em que o aluno tem que construir um conceito novo a partir de seu nível de competência que está sendo desenvolvido sob a influência de um determinado contexto histórico-cultural.

Sendo assim, a educação mediada por tecnologias funda-se no diálogo, na autoria e na presença de um professor que tem o papel de orientador do processo de aprendizagem dos alunos. Ou seja, o professor ativo é o potencializador para que esse processo funcione, por isso ele precisa saber o que está fazendo e o que é essencial ao planejar as ações em torno das atividades de estudo para organizá-las de maneira correta, promovendo o desenvolvimento cognitivo de seus alunos.

É importante ressaltar que nesse trabalho de investigação-ação o curso foi implementado com planejamento e orientações por parte dos professores-formadores durante a realização das tarefas de estudo, resultando na produção e implementação de material didático pelas professsoras-alunas, tendo a Internet como repositório de saber. Essas professoras planejaram e implementaram aulas em suas turmas de atuação ao final da capacitação. Isso significa dizer que, ao final do trabalho realizado, tiveram como atividade final e avaliativa a tarefa de elaborar uma aula (buscando materiais através da mediação tecnológica) e implementá-la em suas turmas. Ou seja, realizamos uma avaliação do processo de ensino-aprendizagem, como também do potencial mediador do AMEM.

Ressaltamos que, apesar dos professores-formadores estarem orientando e direcionando as atividades, as dificuldades com a mediação tecnológica aconteceram, até por ser uma experiência nova para as professoras-alunas. Por exemplo, no momento que precisavam enviar uma tarefa extra classe (TE), tinham dificuldade até de digitar no campo específico, perdendo dados ao tentar enviá-la. A atividade de colaboração (AC) passou despercebida ou foi enviada no mesmo campo da TE, ou ainda, perdiam os prazos de envio das tarefas e não lançaram mão da ferramenta mensagem para solicitar ajuda. Quando tiveram que participar de um fórum da disciplina novamente tiveram dificuldades com a navegabilidade do AMEM. Devido a isso, torna-se fundamental o professor estar sempre acompanhando e orientando 
seus alunos para que eles superem as dificuldades e não desistam das aulas. Imagine se não acontecesse esse acompanhamento, de que forma saberíamos se as professorasalunas estavam aprendendo e quais eram suas dificuldades?

Apesar dos problemas com a mediação tecnológica, eles eram minimizados com a familiarização e manejo das ferramentas. Os fatores que contribuíram para obtenção de resultados positivos foram: proposta didático-metodológica e planejamento das aulas; acompanhamento e monitoramento constante pelos professores-formadores das atividades do curso, estimulando a participação e a realização das tarefas; diálogo com o grupo em torno das dificuldades encontradas e na busca de soluções em conjunto com elas; atendimento personalizado; interesse prévio das professoras-alunas por atividades mediadas tecnologicamente; observação e reflexão constante em torno de todo o processo formativo, estudo e problematização dos temas em situações de formação prática.

\section{Considerações Finais}

Diante disso, as atividades de estudo necessariamente precisam ter mediação tecnológica, com suas finalidades, conteúdos planejados (em torno de ações e operações) e diretividade. Essas atividades estão envolvidas em problematizações, acompanhamento e monitoramento por parte do professor (acompanhando os avanços e obstáculos de aprendizagem) e um processo avaliativo em torno do que está sendo feito. Devido a essas ações, implementamos um curso de capacitação que promoveu aos professores-alunos a possibilidade de vivenciarem um processo de formação significativo, aprendendo novas metodologias e conseqüentemente, explorando novos recursos objetivando a melhoria da prática docente. Acreditamos que uma boa escolarização faz diferença na vida dos sujeitos, assim como uma capacitação para trabalhos mediados também precisa ser dessa forma, precisa fazer a diferença na atuação dos professores.

Devido a isso, planejar atividades de estudo que abram caminhos para o diálogo, a problematização e a participação dos alunos sob a condução do professor são fundamentais para que o mesmo promova a aprendizagem e acompanhe o desenvolvimento dos alunos para que, a partir desse acompanhamento, construa novas atividades proporcionando espaços de interação, autoria e o trabalho de produção coletiva. Dessa forma, supera as práticas "bancárias" e dispõe-se ao diálogo com seus alunos, pois ações passivas (mecânicas) ou de memorização não são consideradas como tarefas de aprendizagem desenvolvimental.

\section{BIBLIOGRAFIA}

ABEGG, I. Redes e Ambientes na Educação Científica e Tecnológica na Escolaridade Fundamental. Ante-Projeto de Doutorado. Santa Maria, 2005.

ABEGG, I.; DE BASTOS, F.; MALLMANN, E. M. Momentos pedagógicos dialógicoproblematizadores: sendo desafiados nas aulas. Santa Maria, 2001. Disponível em: $<\mu$ http://amem.ce.ufsm.br§>.

ALMEIDA, Maria Elizabete Biancocini. Tecnologia e educação a distância: Abordagens e contribuições dos ambientes digitais e interativos de aprendizagem. Rio de Janeiro:ANPED, 2003. 
BELLONI, Maria Luiza. Educação a distância. 3. ed. Campinas, São Paulo: Autores Associados, 2003.

BRASIL. Relatório da Comissão de Assessoria de Educação Supeior a Distância. Secretaria de Educação a Distância (SEED), Ministério da Educação, Brasília, 2002. (Em URL: http://www.mec.gov.br).

DAVIDOV, Vasili. La Enseñanza Escolar y el desarrollo Psíquico: Investigación psicológica teórica y experimental. Moscu: Editorial Progreso, 1988.

DE BASTOS, Fábio da Purificação; MAZZARDO, Mara Denize; ALBERTI, Taís Fim. Ambientes Virtuais de Ensino-Aprendizagem: Os Desafios dos Novos Espaços de Ensinar e Aprender e suas Implicações no Contexto Escolar. Revista Novas Tecnologias na Educação (RENOTE) CINTED/UFRGS, vol. 3, №. 1, mai/2005. Disponível em <http://www.cinted.ufrgs.br/renote/maio2005/artigos/a22 ensinoaprendizagem.pdf>.

DE BASTOS, Fábio da Purificação; MÜLLER, Felipe Martins; CORDENONSI, André Zanki. O Ensino de Heurísticas e Metaheurísticas na Área de Pesquisa Operacional sob a Ótica da Educação Dialógica Problematizadora. Revista Novas Tecnologias na Educação (RENOTE) CINTED/UFRGS, vol. 3, №. 1, mai/2005. Disponível em $<$ http://www.cinted.ufrgs.br/renote/maio2005/artigos/a35 heuristica.pdf>

DOWBOR, Ladislau. Tecnologias do conhecimento: os desafios da educação. Petropólis, Rio de Janeiro: Vozes, 2001.

FERNANDÈZ, Edgard G. Ambiente Multimídia Para Educação Mediada Por Computador: Modelagem e Implementação. Dissertação de Mestardo. PPGEP, UFSM, 2003.

FREIRE, P. Pedagogia do oprimido. Rio de Janeiro, Paz e Terra, 1987.

GIL PÉREZ, D. e VALDÉS CASTRO, P. La Resolución de Problemas de Física: de los exercicios de aplicación al tratamento de situaciones problemáticas. Revista Enseñanza de la Física, 1997, v. 10 (2) pp: 5-20.

LEONTIEV, A. N. Actividad, conciencia y personalidad. Editorial Pueblo y Educación. Ciudad de la Habana, 1983.

MAZZARDO, M. D. Investigando as Potencialidades dos Ambientes Virtuais de EnsinoAprendizagem na Formação Continuada de Professores. Dissertação de Mestrado. PPGE/UFSM, 2005.

MÜLLER, Felipe; DE BASTOS, Fábio Da Purificação. Matriz dialógica-problematizadora como ferramenta organizadora do trabalho escolar no AMEM. In: Congresso Nacional de Ambiente Hipermídia para Aprendizagem, 2004. Anais do Congresso Nacional de Ambiente Hipermídia para Aprendizagem, Florianópolis-SC, 2004. 1 CD-ROM.

RAYS, Oswaldo Alonso (org.). Educação: ensaios reflexivos. Santa Maria/RS: Pallotti, 2002. 
SILVA, Marco(org.). Sala de aula interativa. 3ª. ed. Rio de Janeiro: Quartet, 2002.

SILVA, Marco (org.). Educação online: teorias, práticas, legislação e formação de professores. Rio de Janeiro: Loyola, 2003.

VALENTINI, Carla Beatris; SOARES, Eliana Maria do Sacramento. (orgs). Aprendizagem em ambientes virtuais: Compartilhando idéias e construindo cenários. Editora: EDUCS, Caxias do Sul, 2005.

VYGOTSKY, L. S. A formação social da mente. Livraria Martins Fontes Editora Ltda. São Paulo, 1989.

'Conforme o dicionário de espanhol "El pequeño Larousse" o termo rectora significa pessoa que governa ou sinaliza a direção ou orientação de algo (2002, p. 860). 